\title{
Stick or grip? Co-evolution of adhesive toepads and claws in Anolis lizards
}

\section{Citation}

Crandell, Kristen E., Anthony Herrel, Mahmood Sasa, Jonathan B. Losos, and Kellar Autumn. 2014. "Stick or Grip? Co-Evolution of Adhesive Toepads and Claws in Anolis Lizards." Zoology 117 (6) (December): 363-369. doi:10.1016/j.zool.2014.05.001.

\section{Published Version}

doi:10.1016/j.zool.2014.05.001

\section{Permanent link}

http://nrs.harvard.edu/urn-3:HUL.InstRepos:20444690

\section{Terms of Use}

This article was downloaded from Harvard University's DASH repository, and is made available under the terms and conditions applicable to Open Access Policy Articles, as set forth at http:// nrs.harvard.edu/urn-3:HUL.InstRepos:dash.current.terms-of-use\#OAP

\section{Share Your Story}

The Harvard community has made this article openly available.

Please share how this access benefits you. Submit a story.

\section{Accessibility}


1 Stick or grip? Co-evolution of adhesive toepads and claws in Anolis lizards

2 Kristen E. Crandell ${ }^{1}$, Anthony Herrel2,3, Mahmood Sasa ${ }^{4,5}$, Jonathan B. Losos ${ }^{6}$, Kellar 3 Autumn $^{7}$

4

5 1.Field Research Station at Fort Missoula, Division of Biological Sciences, University 6 of Montana, Missoula, MT 59812, USA

$7 \quad$ email : kristen.crandell@umontana.edu

8 2. UMR 7179 C.N.R.S/M.N.H.N., Département d'Ecologie et de Gestion de la

9 Biodiversité, 57 rue Cuvier, Case postale 55, 75231, Paris Cedex 5, France.

10 3. Ghent University, Evolutionary Morphology of Vertebrates, K.L. Ledeganckstraat 11 35, B-9000 Gent, Belgium

12 4. Palo Verde Biological Station, Organization for Tropical Studies, 0676-2050 San

13 Jose, Costa Rica

14 5. Instituto Clodomiro Picado, Universidad de Costa Rica, San Jose, Costa Rica

15 6. Museum of Comparative Zoology and Department of Organismic and Evolutionary

16 Biology, Harvard University, 26 Oxford Street, Cambridge, MA 02138, USA

17 7. Department of Biology, Lewis \& Clark College, Portland, OR 97219, USA

\section{Pages: 16}

19 Figures: 6

20 Tables: 1

21 Key Words: Anolis; adhesion; claw; toepad; ecomorphology; clinging; mainland 


\section{ABSTRACT}

24

25

26

27

28

29

30

31

32

33

34

35

36

37

38

39

40

41

42

43

44

45

46

47

48

49

50

Exploring the relationship between phenotype and performance in an ecological and evolutionary context is crucial to understand the adaptive nature of phenotypic traits. Despite their ubiquity in vertebrates, few studies have examined the functional and ecological significance of claw morphologies. Here we examine the adhesive toepad and claw system of Anolis lizards. Claw characters are significantly different between lizards classified as arboreal (perch height $>1 \mathrm{~m}$ ) and non-arboreal (perch height $<1 \mathrm{~m}$ ). Arboreal species possess significantly higher and longer claws, and show trends toward decreased claw curvature and wider claw tip angles. Toepad size and claw length and height are tightly correlated with each other and with perch height, suggesting that the adhesive toepad and gripping claw have co-evolved to accommodate different habitats. The functional morphology and evolution of claws are ripe areas for future investigation.

\section{INTRODUCTION}

Studying the link between phenotype and performance is necessary for insight in to the adaptation of form and function Arnold, 1983. The functional significance of claws is not well studied, despite their ubiquity throughout vertebrates. Claws are known to increase available habitat Cartmill, 1974, yet the link between morphological and habitat use variation is unknown. Here, we explore the claw in relation to a second structure used in attachment, the adhesive toepad,

43 in Anolis lizards.

4 Anoles are an ideal model organism with which to unravel potential 45 ecological contributions of claws, as they occupy a vast array of habitats with 46 predictable evolutionary trajectories Losos, 2009. Anolis lizards comprise a

47 diverse clade that has undergone adaptive radiation on the Caribbean islands of the

48 Greater Antilles, producing species of similar ecology and morphology termed

49 "ecomorphs" that have evolved independently on each island Williams, 1983. 
51 between morphology, performance, and ecology (see Losos, 2009 for a review). A

52 particularly striking feature of anoles is the adhesive toepad, which enables the

53 animal to move across smooth substrates with little difficulty. Toepads are thought

54 to be a key innovation in anoles because their evolution may have allowed these

55 lizards to occupy a larger portion of the available habitat than previously possible,

56 thus permitting their radiation and diversification (Warheit et al., 1999.

Toepads are effective in permitting anoles to expand their habitat use due to

58 their attachment abilities: they function best on smooth surfaces, such as leaves and

59 smooth tree bark. Microscopic hair-like structures on the ventral pad, termed setae,

60 adhere to substrates via van der Waals forces Autumn et al., 2002, Puthoff et al.,

612010 . Among anole species, clinging ability varies with habitat use. Species that

62 occur higher in the tree canopy possess larger toepads, and are capable of producing

63 greater shear forces Elstrott and Irschick, 2004, Macrini et al., 2003). This variation

64 suggests that the evolution of adhesive toepads may have been critical for

65 occupation of arboreal habitats, and thus may have played a major role in the

66 diversification of Caribbean anoles into a distinct set of ecomorphs.

67 An often-neglected feature of Anolis relevant to clinging is their claws. Like

68 almost all other lizard species, anoles possess claws, and variation in claw

69 morphology may be related to differences in habitat use. Unfortunately, claws have

70 been overlooked not only in anoles, but also in most amniotes. Vertebrates with

71 claws can occupy larger portions of the habitat than non-clawed animals Cartmill,

72 1974. However, the functionality of claws is less understood (see Maddin and Reisz,

732007 and Zani, 2000. Some aspects of claw shape are known to affect attachment

74 ability, including claw height (the distance measured from dorsal to ventral at the

75 base of the claw Zani, 2000. In animals such as beetles, claws interact with surface

76 irregularities in two ways: interlocking and friction. When surface irregularities are

77 larger than claw tip diameter, the claw mechanically interlocks with the

78 irregularities. In contrast, when surface irregularities are smaller than claw tip

79 diameter, attachment results from frictional forces. In this instance, if the tangent 
80 between the claw and the irregularity is too low, the claw slips Dai et al., 2002. As

81 such, mechanical interlocking (accomplished with a smaller claw tip relative to

82 substrate roughness) is often times stronger than frictional attachment, with a

83 lower likelihood of failure. Thus, the ability to create a mechanical attachment,

84 rather than a friction-based attachment, is improved with smaller claw tips.

85 Decreasing the size (or effective angle) of the tip increases the likelihood of surface

86 irregularities being larger, offering more opportunity for mechanical attachment. In

87 fact, in artificial claws, decreasing the tip's effective angle significantly improves the

88 strength of attachment Provancher et al., 2004.

However, understanding the broader relationship between claw morphology

90 and habitat use is not yet possible. A study linking claw morphology directly to

91 habitat use in birds indicates that ground-dwelling species have significantly less

92 curved claws than perching species, and species that climb have claws with higher

93 curvature than both ground and perch dwellers Feduccia, 1993. Similar patterns

94 have been observed in lizards: arboreal and saxicolous species have claws with

95 higher curvature Tulli et al., 2009. Some additional evidence for the importance of

96 claws exists in a single species, the ecologically variable Anolis cybotes; individuals

97 in more rocky areas appear to have more curved claws (Wollenberg et al., 2013.

98 It is reasonable to predict that the claw and adhesive toepad operate under

99 disparate conditions. The toepad functions best on relatively smooth, homogenous

100 surfaces. The attachment between microscopic hair-like structures of the ventral

101 pad and the surface is modeled to be maximal on smoother surfaces Persson and 102 Gorb, 2003, Russell and Johnson, 2013, and performance declines with increasing

103 surface roughness (Vanhooydonck et al., 2005). In contrast, claws appear to

104 maximize functionality on very rough surfaces, where mechanical interlocking of

105 the claw is often-times stronger than friction forces on smoother surfaces Dai et al., 106 2002. Thus, it appears both structures are optimal in two different scenarios. This 107 observation was first put forth by Mahendra 1941, who observed following claw 108 removal, Hemidactylus geckos were unable to attach to rough surfaces, but 
109 attachment to smooth surfaces was unaffected. Further recent explorations are

110 limited, but best evidenced in an analysis of performance and morphology. Zani

111 (2000) found that in 85 species of lizard, toe width and lamellae number is

112 correlated with attachment ability to smooth surfaces, while claw height is

113 correlated with rough surface attachment.

114 Examining both the adhesive toepad alongside the claw may reveal ecological

115 patterns hitherto unknown, or previously overlooked and attributed to toepad

116 function alone. Here, we explore the relationship between toepad clinging ability,

117 claw morphology, and habitat use in Anolis. We test for associations between claw

118 morphology and habitat use. We predict that arboreal species with higher perch

119 heights will have claw morphologies associated with improved attachment abilities:

120 higher and longer Zani, 2000, more curved Feduccia, 1993, and sharper tips Dai

121 et al., 2002. We also test if phylogenetically corrected features of claws that are

122 thought to improve attachment co-vary with toepad adhesion ability, given that

123 toepads also correlate with habitat Elstrott and Irschick, 2004. Our available

124 lizards are mainland species, and as such we also confirm that mainland species

125 follow the same trends as island species by testing for a positive relationship

126 between toe force production and perch height Irschick et al., 1997, Macrini et al.,

1272003.

128

129 METHODS

130 Study area and species

131 Fieldwork occurred at La Selva Biological Station, Playa Piro, and Palo Verde

132 Biological Station in Costa Rica, and Gamboa, Panama. A total of 12 species was

133 studied (see table 1). To capture animals and determine perch height, we walked

134 along trails daily when lizards were active and recorded data for any individual

135 sighted. Perch height was measured as distance from the ground to the individual's 
136 original position, and perch diameter was measured at the location the lizard was

137 first observed. Lizards were captured by hand or noose and kept for no longer than

13848 hours. Lizards were kept in one-gallon plastic bags, transported to the field lab

139 and returned to their original location following performance trials.

140 Adhesion performance

141 Following capture, one person (KEC) took shear-force measurements. A dual-

142 range force sensor (Vernier) was attached to a vertical acetate covered glass

143 microscope slide with a custom plexiglass attachment and butterfly clip. For each

144 subject, the fourth (longest) digit was isolated and gently applied to the acetate

145 sheet (Fig. 1). These performance measures only reflect attachment ability of the

146 adhesive toepad, not the claw, because the claw was not able to penetrate the

147 acetate coating. The anole was pulled by hand at an approximately constant speed,

148 and the shear force was recorded at $40 \mathrm{~Hz}$. Each subject underwent three repeated

149 trials for left and right fourth toe.

150 Morphology

151 For all species in this study, we measured toepad and claw morphological

152 characters from preserved specimens at the Museum of Comparative Zoology,

153 Harvard University, and specimens from the Museum of Southwestern Biology,

154 University of New Mexico (see appendix for list). A scanner (Epson Perfection 4900

155 and V500) digitized images of the fourth right hind digit, with the claw flattened

156 sagitally against the scanner. Measurements were taken with Image J (1.4g,

157 Rasband). Morphological characters of the toe included toepad area, measured from

158 where the pad begins to widen (i.e., where the next most distal lamellae is longer

159 than the previous), and lamellae number, counted as lamellae contained within

160 toepad area. Measurements of the claw included: height, length, curvature (as

161 measured by Zani, 2000), and tip angle (Fig. 2).

162 
Analysis

164

For all species, we determined descriptive statistics for all continuous

165 characters. To meet assumptions of normality and homoscedasticity, all

166 measurements except for toepad force and claw tip angle were log-10 transformed

167 prior to analysis. We corrected for size in characters that significantly correlated

168 with SVL. To do so, we regressed log-10 adjusted values against log-10 adjusted SVL

169 and calculated residuals, which were used for subsequent regressions.

170

A bivariate Pearson correlation on the log-10 transformed data was used to 171 determine correlations among traits. Log-10 transformed data were then used as 172 input for an independent contrasts analysis Felsenstein, 1985 using the GEIGER 173 package in R Harmon et al., 2008. The most complete phylogenetic tree of Anolis 174 Nicholson et al., 2005/ served as the basis for analyses (Fig. 3). Panamanian species 175 described in Castañeda and de Queiroz (2013) were added as sister taxa, and Anolis 176 apletophallus was placed as sister taxon to Anolis limifrons (S. Poe, pers. comm.). 177 Branch lengths of the phylogeny were unknown, and were set to arbitrary lengths 178 using a Grafen transformation Grafen, 1989. The calculated residual values of 179 morphological, performance, and habitat use variables were input into a linear 180 regression analysis to determine correlation coefficients. An analysis of variance 181 (ANOVA) tested for statistical significance for all regressions. All analyses presented 182 account for phylogeny.

183 We also compared claw variables between two groups of anoles classified as 184 "arboreal" or "non-arboreal." Arboreal species were defined as those with an 185 average perch height greater than one meter, whereas non-arboreal were those 186 found perching below one meter. Species with mean perch heights less than one 187 meter are generally seen on or near the ground, whereas those above one meter are 188 those that are often seen in the canopy. Claw morphologies (claw curvature, claw tip 189 angle, claw height, and claw length) were first compared with a phylogenetically 190 corrected MANOVA. Each character was then compared between groups with a 191 phylogenetically corrected ANOVA. One-tailed tests were used in all comparisons, as 
192 we had a-priori predictions for claw curvature Feduccia, 1993, claw tip angle Dai 193 et al., 2002, and claw height and length Zani, 2000. It should be noted that Zani 194 (2000) found the correlation between claw length and clinging ability on rough 195 surfaces was not robust to changes in phylogenetic branch lengths in one out of four 196 models. Both phylogenetic analyses used the GEIGER package in R Harmon et al., 197 2008.

Morphology and performance

Table 1 lists the mean \pm SE for all morphological variables and toepad force 201 production. All variables were size corrected, with analyses performed on the 202 residuals of the data regressed against body size (see methods), with the exception 203 of claw tip angle $\left(\mathrm{p}=0.68, \mathrm{r}^{2}=0.02\right)$ and claw curvature $\left(\mathrm{p}=0.91, \mathrm{r}^{2}=0.001\right)$, because 204 they were uncorrelated to overall body size. All correlations are the result of 205 phylogenetically independent contrasts to account for ancestral relatedness.

206 Adjusted toepad area correlates positively with the size adjusted variables 207 claw height $\left(p<0.001, r^{2}=0.65\right.$, d.f. $\left.=1,10\right)$, claw length $\left(p=0.03, r^{2}=0.35\right.$, d.f. $\left.=1,10\right)$, 208 and non-size adjusted claw curvature $\left(\mathrm{p}=0.05, \mathrm{r}^{2}=0.26\right.$, d.f. $\left.=1,10\right)$. Pad area also 209 correlates positively with toepad force production following corrections for size $210\left(\mathrm{p}<0.001, \mathrm{r}^{2}=0.75\right.$, d.f. $\left.=1,10\right)$. Toepad lamella number exhibits similar relationships, 211 correlating positively with claw height $\left(\mathrm{p}=0.02, \mathrm{r}^{2}=0.42\right.$, d.f. $\left.=1,10\right)$, claw length $212\left(p=0.03, r^{2}=0.38\right.$, d.f. $\left.=1,10\right)$, and toepad force production $\left(p<0.001, r^{2}=0.83\right.$, 213 d.f. $=1,10)$.

214 A positive correlation also occurs between toepad force production and claw 215 height $\left(\mathrm{p}=0.01, \mathrm{r}^{2}=0.51\right.$, d.f. $\left.=1,10\right)$ and claw length $\left(\mathrm{p}=0.02, \mathrm{r}^{2}=0.46\right.$, d.f. $\left.=1,10\right)$ (Fig. 216 4). Force production and claw curvature are also related, but the relationship is not 217 statistically significant $\left(\mathrm{p}=0.08, \mathrm{r}^{2}=0.30\right.$, d.f. $\left.=1,9\right)$. No relationship is present 218 between force production and claw tip angle $\left(\mathrm{p}=0.98, \mathrm{r}^{2}<0.0001\right.$, d.f. $\left.=1,10\right)$. 
220 A positive correlation exists between perch height and toepad shear-force $221\left(\mathrm{p}=0.006, \mathrm{r}^{2}=0.58\right.$, d.f.=1,9) (Fig. 5), but no correlation occurs between adjusted 222 force production and perch diameter $\left(\mathrm{p}=0.22, \mathrm{r}^{2}=0.16\right.$, d.f. $\left.=1,9\right)$. Perch height does 223 not linearly correlate with claw variables, including claw height $\left(\mathrm{p}=0.43, \mathrm{r}^{2}=0.07\right.$, 224 d.f. $=1,9)$, claw length ( $\mathrm{p}=0.26, \mathrm{r}^{2}=0.14$, d.f. $\left.=1,9\right)$, claw curvature $\left(\mathrm{p}=0.56, \mathrm{r}^{2}=0.04\right.$, 225 d.f. $=1,9)$, and claw tip angle $\left(p=0.90, r^{2}=0.002\right.$, d.f. $\left.=1,9\right)$.

226 We also compared claw variables with binomially categorized habitat by 227 dividing anoles in to two classes: "arboreal," with average perch heights of over one 228 meter, and "non-arboreal," with average perch heights below one meter. We found 229 general trends in all claw morphologies between our arboreal categories 230 (phylogenetic MANOVA $\mathrm{p}=0.054$ ). Claw tip angle was close to statistically different 231 between categories ( $p=0.054$, Fig. 6A), as was claw curvature ( $p=0.054$, Fig. 6B).

232 Both claw height ( $p=0.007$, Fig. 6C) and claw length ( $p=0.029$, Fig. 6D) were 233 statistically significantly different between groups.

DISCUSSION

Our study is one of the first to examine toe and claw morphology in a 237 vertebrate with an eye towards performance in a natural environment. We find 238 support for both of our hypotheses. First, the adhesive toepad of Anolis species co239 varies with claw morphology. Secondly, all claw characters measured are associated 240 with habitat use.

241 We found strong evidence for co-evolution between adhesive toepads and 242 claws in size-corrected correlations between toepad size and claw height and length 243 (Fig. 4). Adhesive toepads and claws provide clinging capability in different 244 substrate conditions: smooth and rough, respectively. Arboreal animals encounter 245 both types of surfaces as they move on leaves, a smooth substrate, and woody 
246 vegetation, a rough substrate; hence, it is not surprising that more arboreal species, 247 needing greater attachment ability, should have better developed claws and toepads.

248 We found strong trends and significant differences between species grouped 249 as arboreal (mean perch height $>1 \mathrm{~m}$ ) and non-arboreal (mean perch height $<1 \mathrm{~m}$ ). 250 A phylogenetic MANOVA of all claw morphologies came very close to statistical 251 significance at $\mathrm{p}=0.054$, indicating that claw characters are likely related to perch 252 height. With phylogenetic ANOVAs for each character, we were able to dissect this 253 trend. Claw curvature and claw tip angle were not statistically significant between 254 groups, but both showed major trends in that direction, with $\mathrm{p}$ values very close to, 255 but slightly above, 0.05 . This trend does not fall in line with increased claw 256 curvature in arboreal birds in comparison to ground-dwelling birds (Feduccia, 257 1993. Given that claw sharpness (measured here as a smaller tip angle) improves 258 attachment ability Dai et al., 2002; Provancher et al., 2004, it is also surprising that 259 arboreal species trend toward less pointed claw tips. We predict with larger sample 260 sizes, a significant trend would appear. These differences suggest further studies 261 examining claw function are vital. Both claw height and length were significantly 262 different between the two groups (Fig. 5). Claw height improves attachment ability 263 on rough surfaces Zani, 2000. Interestingly, adhesive pad area is also correlated 264 with perch height Elstrott and Irschick, 2004. Together, differences in claw shape 265 and toepad function in comparison to perch height serve as further evidence for the 266 co-evolution between claws and pads.

267 Despite strong differences between arboreal and non-arboreal morphologies, 268 we did not find linear correlations between claw characters and perch height in this 269 study. Arboreality implies a heightened need for both attachment systems, to 270 maintain attachment during motion and to avoid falling. However, the functionality 271 of these systems differs in their basic attachment mechanics. In particular, the 272 toepad area is continuous with an increase in surface area of the pad resulting in an 273 increase in clinging ability. In contrast, claw function may not be continuous - once 274 a certain threshold is reached in size or shape, an increase in size or further changes 
275 in shape may confer no more functional, and therefore selective, advantage. For 276 example, higher claws may serve no better than slightly lower ones, as both are 277 capable of mechanical interlocking with the substrate. This is in sharp contrast with 278 toepad area, where increased size confers a linear increase in force. Thus, certain 279 morphologies will be able to accommodate rough substrates, without regard to the 280 actual perch height.

Our study focused on the two ecological standards for anoles: perch height 282 and diameter. While we found several intriguing patterns with perch height, none 283 of our measured variables correlated with perch diameter. In a study by Macrini et 284 al. (2003), perch diameter in mainland and island anoles correlates with pad area. 285 However, we found no such relationship here. Mainland species vary in habitat use, 286 and with our relatively small sample size, such patterns may not appear due to 287 higher ecological variation of mainland anoles Schaad and Poe, 2010. Further, 288 variation in claws may not reflect ecological differences on such a minor scale. In 289 order to stay attached to a vertical perch, the forces produced by pushing the left 290 and right limbs in to the perch must be 90 degrees or less in order to support body 291 weight. Claws are known to help reduce this effective angle Biewener, 2003 292 Cartmill, 1974. However, at perch diameters less than a body width, where most of 293 our species were observed, claws are not necessary as the angle between limbs is 294 much less than 90. Thus, a non-existent relationship between perch diameter and 295 claw morphologies agrees with theory. Claw characters may prove important in ecological contexts not reported in 297 this study. In particular, claw height improves attachment ability on rough surfaces 298 Zani, 2000. Thus, we predict that improved claw morphology (height, length, 299 curvature, and sharpness) is also correlated with surface roughness. This prediction 300 is opposite that which is known in adhesive toepads, which function best on smooth 301 surfaces Vanhooydonck et al., 2005. Further, the functional interaction of claw 302 and substrate is unknown. Claws may be used to actively pierce substrates, or attach 303 solely due to passive friction. If claws are used to pierce, our results may be 
304 confounded by the wearing-down of the claw structure, as observed in artificial 305 claw systems Provancher et al., 2004. Use of the claw is likely to vary with size and 306 morphology of the vertebrate, as well as locomotor style. For example, birds show a 307 variety of toe organizations - varying from one to two opposing toes in various 308 configurations. Alongside the differences in muscular arrangement of the flexors 309 and extensors, this variation may influence whether the claw is actively piercing or 310 passively attaching to a substrate. Body size and shape has the potential to further 311 confound claw use. For example, in four-legged vertebrates, the smaller species 312 tend to have a more sprawled posture, while larger species are more upright 313 Biewener, 1989. The distance and angle between opposing limbs likely affects the 314 effective angle of the claw relative to the substrate - especially on substrates with a 315 limited diameter Cartmill, 1974. Behavioral and ecological data in lizards would 316 shed light on claw use, body size, and locomotion, yet are lacking for most of the 317 species studied here. For studies outside of Anolis, understanding body size, posture,

318 and foot morphology will be crucial to compare claw morphologies across taxa.

319 Lastly, although not the focus of our study, we found that mainland anoles 320 studied here show similar ecological patterns to island species. In island species, 321 toepad force production positively correlates with perch height Elstrott and 322 Irschick, 2004. This potential trend was unknown in mainland species, particularly 323 because mainland species have dramatically smaller adhesive toepads Macrini et al., 324 2003. Whether or not this difference in size indicates mainland species have less 325 clinging ability remains to be tested, as island studies are not comparable to our 326 data and appear more variable in sampling technique. Moreover, our study focused 327 on a single digit, while previous studies measured force production in the 10 328 forelimb digits Irschick et al., 1996. Additionally, mainland species might 329 experience more diversity in textures and selection for claw characters might not be 330 as strong as in an island setting. Understanding potential differences and similarities 331 between clades is of particular interest, as island and mainland species appear to 332 have different patterns of morphological variation Schaad and Poe, 2010; |Velasco 333 and Herrel, 2007). 
$334 \quad$ Further studies exploring both mainland and island species in tandem are 335 necessary to elucidate how toepad morphologies differ between populations. Such 336 studies must use caution when collecting or comparing adhesion performance data 337 to previously published values. Our data were collected in the field and may have 338 been influenced by environmental conditions including humidity, which may reduce 339 Niewiarowski et al., 2008, Stark et al., 2012 or increase Chen and Gao, 2010, 340 Pesika et al., 2009;| Prowse et al., 2011,| Puthoff et al., 2010 clinging ability in 341 biological adhesives. In particular, high humidity environments change the 342 mechanical properties of the microscopic setae, increasing adhesion abilities 343 Prowse et al., 2011; Puthoff et al., 2010. Similarly, increased stress of being 344 sampled in the field may impair performance. Further studies across Anolis with 345 standardized methods, alongside increased sample sizes, will improve our 346 understanding of relationships among pad, claw, and habitat use.

$347 \quad$ Here we have shown the ecological importance of claw morphology. Anoles 348 found higher in the forest have longer and higher claws, with trends toward 349 decreased claw curvature and increased claw tip angle. These results indicate the 350 importance of claws to habitat use. As almost all vertebrates have claws, this 351 character is ripe for further study. Our study also indicates that claws and adhesive 352 toepads have coevolved in Anolis. However, they likely serve partially differing 353 functions; a hypothesis that requires further research on the interaction between 354 the toe and natural surfaces. Understanding this interaction will entail an 355 integration of micro-scale studies of single foot-hairs Autumn, 2006, Autumn et al., 356 2000; Liang et al., 2000 and claw tips (Dai et al. 2002) with macro-scale studies of 357 the interaction between a variety of natural and artificial surfaces with whole claws 358 (Provancher et al. 2004) and toepads. 


\section{Acknowledgements}

363 Field work was arranged through the Organization for Tropical Studies, Duke University, 364 Guido Saborío from Amigos de Osa, and the Smithsonian Tropical Research Institute, 365 under research permit numbers SINAC 123-2008 del Ministerio del Ambiente y Energia 366 - Sistema Nacional de areas de Conservacion and SE/A-64-09 del Autoridad Nacional 367 del Ambiente de Panama. The authors thank Shane Campbell-Staton, Kristi

368 Fenstermacher, Hannah Frank, Martha Muñoz, Stephane Montuelle, Paul

369 VanMiddlesworth, and Katharina Wollenberg for help in the field. For access to 370 specimens, we thank Jose Rosado, Luke Mahler (MCZ, Harvard University), Steve Poe, 371 and Tom Giermakowski (MSB, University of New Mexico). Greta Binford provided 372 feedback on a previous draft. We thank four anonymous reviewers. Use of animals in 373 this study was approved by Lewis \& Clark College IACUC (ACUP-2008-001). This 374 research was funded by Sigma Xi (G200803150489 to KEC), Lewis \& Clark College 375 SAAB (to KEC), and the National Science Foundation (NSF-NIRT 0304730, NSF-IOS376 0847953, NSF_NBM-0900723 and Special Creativity Award to KA; NSF DEB-0444763 377 to JBL).

378

379

380

381

382

383

384

385

386

387

388

389

390

391

392

393

394

395

396

397

398

399

400

401

402

403

404

405

406 
410 Figure 1. Anolis sagrei hanging on a glass slide by a single toe.

Figure 2. Morphological characteristics determined for each digit. Claw height $=$ length 414 curvature $=57.296 *\left(2 * \operatorname{arcsine}\left(\left(\left(2 * \mathrm{C}^{2 *} \mathrm{D}^{2}\right)+\left(2 * \mathrm{~B}^{2 *} \mathrm{D}^{2}\right)+\left(2 * \mathrm{~B}^{2 *} \mathrm{C}^{2}\right) \pm \mathrm{B}^{4} \pm \mathrm{C}^{4} \pm \mathrm{D}^{4}\right)^{0.5}\right.\right.$ $415 /(2 * \mathrm{C} * \mathrm{D})))$ (modified from Zani, 2000)

Figure 3. Phylogenetic relationships of the 12 species in this study, modified from Nicholson et al. (2005). Branch lengths do not reflect distance.

Figure 4. Independent contrasts showing how toepad force production is correlated with claw height (A) and claw length (B), suggesting that both features have co-evolved in mainland Anolis lizards.

Figure 5. Independent contrasts showing that toepad force production is correlated with perch height in mainland Anolis lizards, illustrating that both traits have coevolved.

Figure 6. Claw morphological characters for species classified as arboreal (average perch height $>1$ meter) and non-arboreal (average perch height $<1$ meter). Claw curvature (a) and tip angle (b) are not statistically significantly different, but claw height (c) and length (d) are significantly different between groups.

Table 1. Morphological and performance characters measured for each species. All measurements were taken from the fourth (longest) digit of the right hind foot. Morphological measurements reflect museum specimens (supplement 1), and performance measures were taken from wild-caught individuals. 


\section{References}

455

456

457

458

459

460

461

462

463

464

465

466

467

468

469

470

471

472

473

474

475

476

477

478

479

480

481

482

483

484

485

486

487

488

489

490

491

492

493

494

495
Arnold, S.J., 1983. Morphology, performance, and fitness. American Zoologist 23, 347-361.

Autumn, K., 2006. Properties, principles, and parameters of the gecko adhesive system, in: Smith, A., Callow, J. (Eds.), Biological Adhesives. Springer Verlag, Berlin Heidelberg.

Autumn, K., Liang, Y.A., Hsieh, S.T., Zesch, W., Chan, W.P., Kenny, T.W., Fearing, R., Full, R.J., 2000. Adhesive force of a single gecko foot-hair. Nature 405, 681-685.

Autumn, K., Sitti, M., Liang, Y.C.A., Peattie, A.M., Hansen, W.R., Sponberg, S., Kenny, T.W., Fearing, R., Israelachvili, J.N., Full, R.J., 2002. Evidence for van der Waals adhesion in gecko setae. Proceedings of the National Academy of Sciences of the United States of America 99, 12252-12256.

Biewener, A.A., 1989. Scaling body support in mammals - limb posture and muscle mechanics. Science 245, 45-48.

Biewener, A.A., 2003. Animal Locomotion. Oxford University Press, Oxford, UK.

Cartmill, M., 1974. Pads and claws in arboreal locomotion, in: Jenkins, F.A. (Ed.), Primate Locomotion. Academic Press, New York.

Castañeda, M., de Queiroz, K., 2013. Phylogeny of the dactyloa clade of Anolis lizards:

New insights from combining morphological and molecular data. Bulletin of the

Museum of Comparative Zoology 160, 345-398.

Chen, B., Gao, H., 2010. An alternative explanation of the effect of humidity in gecko adhesion: Stiffness reduction enhances adhesion on a rough surface. International Journal of Applied Mechanics 2, 1-9.

Dai, Z.D., Gorb, S.N., Schwarz, U., 2002. Roughness-dependent friction force of the tarsal claw system in the beetle Pachnoda marginata (Coleoptera, Scarabaeidae). Journal of Experimental Biology 205, 2479-2488.

Elstrott, J., Irschick, D.J., 2004. Evolutionary correlations among morphology, habitat use and clinging performance in Caribbean Anolis lizards. Biological Journal of the Linnean Society 83, 389-398.

Feduccia, A., 1993. Evidence from claw geometry indicating arboreal habits of Archaeopteryx. Science 259, 790-793.

Felsenstein, J., 1985. Phylogenies and the comparative method. American Naturalist $125,1-15$.

Grafen, A., 1989. The phylogenetic regression. Philosophical Transactions of the Royal Society of London Series B-Biological Sciences 326, 119-157.

Harmon, L.J., Weir, J.T., Brock, C.D., Glor, R.E., Challenger, W., 2008. GEIGER: investigating evolutionary radiations. Bioinformatics 24, 129-131.

Irschick, D.J., Austin, C.C., Petren, K., Fisher, R.N., Losos, J.B., Ellers, O., 1996. A comparative analysis of clinging ability among pad-bearing lizards. Biological Journal of the Linnean Society 59, 21-35.

Irschick, D.J., Vitt, L.J., Zani, P.A., Losos, J.B., 1997. A comparison of evolutionary radiations in mainland and Caribbean Anolis lizards. Ecology 78, 2191-2203. 
503

504

505

506

507

508

509

510

511

512

513

514

515

516

517

518

519

520

521

522

523

524

525

526

527

528

529

530

531

532

533

534

535

536

537

538

539
Liang, Y., Autumn, K., Hsieh, S., Zesch, W., Chan, W., Fearing, R., Full, R., Kenny, T., 2000. Adhesion force measurements on single gecko setae. Technical Digest of the 2000 Solid-State Sensor and Actuator Workshop, 33-38.

Losos, J.B., 2009. Lizards in an Evolutionary Tree: ecology and adaptive radiation of anoles. University of California Press, Berkeley, CA.

Macrini, T.E., Irschick, D.J., Losos, J.B., 2003. Ecomorphological differences in toepad characteristics between mainland and island anoles. Journal of Herpetology 37, 52-58.

Maddin, H.C., Reisz, R.R., 2007. Histological microstructure of the claw of the African clawed frog, Xenopus laevis (Anura : Pipidae). Journal of Morphology 268, 11011101.

Mahendra, B.C., 1941. Contributions to the bionomics, anatomy, reproduction and development of the Indian house gecko Hemidactylus faviviridis. Ruppel Part !!. The problem of lcomotion. Proc. Indian Acad. Sci. Sect. B 13, 288-306.

Nicholson, K.E., Glor, R.E., Kolbe, J.J., Larson, A., Hedges, S.B., Losos, J.B., 2005. Mainland colonization by island lizards. Journal of Biogeography 32, 929-938.

Niewiarowski, P.H., Lopez, S., Ge, L., Hagan, E., Dhinojwala, A., 2008. Sticky gecko feet: The role of temperature and humidity. Plos One 3.

Persson, B.N.J., Gorb, S., 2003. The effect of surface roughness on the adhesion of elastic plates with application to biological systems. Journal of Chemical Physics 119, 11437-11444.

Pesika, N.S., Zeng, H.B., Kristiansen, K., Zhao, B.X., Tian, Y., Autumn, K., Israelachvili, J., 2009. Gecko adhesion pad: a smart surface? Journal of Physics-Condensed Matter 21.

Provancher, W.R., Clark, J.E., Geisler, B., Cutkosky, M.R., 2004. Towards penetrationbased clawed climbing, 7th International Conference on Climbing and Walking Robots (CLAWAR 2004), Madrid, Spain.

Prowse, M.S., Wilkinson, M., Puthoff, J.B., Mayer, G., Autumn, K., 2011. Effects of humidity on the mechanical properties of gecko setae. Acta Biomaterialia 7, 733738.

Puthoff, J.B., Prowse, M.S., Wilkinson, M., Autumn, K., 2010. Changes in materials properties explain the effects of humidity on gecko adhesion. Journal of Experimental Biology 213, 3699-3704.

Russell, A., Johnson, M., 2013. Between a rock and a soft place: microtopograph of the locomotor substrate and the morphology of the setal fields of Namibian day geckos (Gekkota: Gekkonidae: Rhoptropus). Acta Zoologica.

Schaad, E.W., Poe, S., 2010. Patterns of ecomorphological convergence among mainland and island Anolis lizards. Biological Journal of the Linnean Society 101, 852-859.

Stark, A.Y., Sullivan, T.W., Niewiarowski, P.H., 2012. The effect of surface water and wetting on gecko adhesion. Journal of Experimental Biology 215, 3080-3086.

Tulli, M.J., Cruz, F.B., Herrel, A., Vanhooydonck, B., Abdala, V., 2009. The interplay between claw morphology and microhabitat use in neotropical iguanian lizards. Zoology 112, 379-392. 
540 Vanhooydonck, B., Andronescu, A., Herrel, A., Irschick, D.J., 2005. Effects of substrate 541 structure on speed and acceleration capacity in climbing geckos. Biological $542 \quad J o u r n a l$ of the Linnean Society 85, 385-393.

543 Velasco, J.A., Herrel, A., 2007. Ecomorphology of Anolis lizards of the Choco' region in $544 \quad$ Colombia and comparisons with Greater Antillean ecomorphs. Biological Journal 545 of the Linnean Society 92, 29-39.

546 Warheit, K.I., Forman, J.D., Losos, J.B., Miles, D.B., 1999. Morphological diversification 547 and adaptive radiation: A comparison of two diverse lizard clades. Evolution 53, 548 1226-1234.

549 Williams, E.E., 1983. Ecomorphs, faunas, island size, and diverse end points in island 550 radiations of Anolis. , in: Huey, R.B., Pianka, E.R., Schoener, T.W. (Eds.), Lizard 551 ecology: Studies of a model organism. Harvard University Press, Cambridge, MA, 552 pp. 132-151.

553 Wollenberg, K.C., Wang, I.J., Glor, R.E., Losos, J.B., 2013. Determinism in the 554 diversification of hispaniolan trunk ground anoles (Anolis cybotes species 555 complex). Evolution.

556 Zani, P.A., 2000. The comparative evolution of lizard claw and toe morphology and 557 clinging performance. Journal of Evolutionary Biology 13, 316-325.

558

559

560 


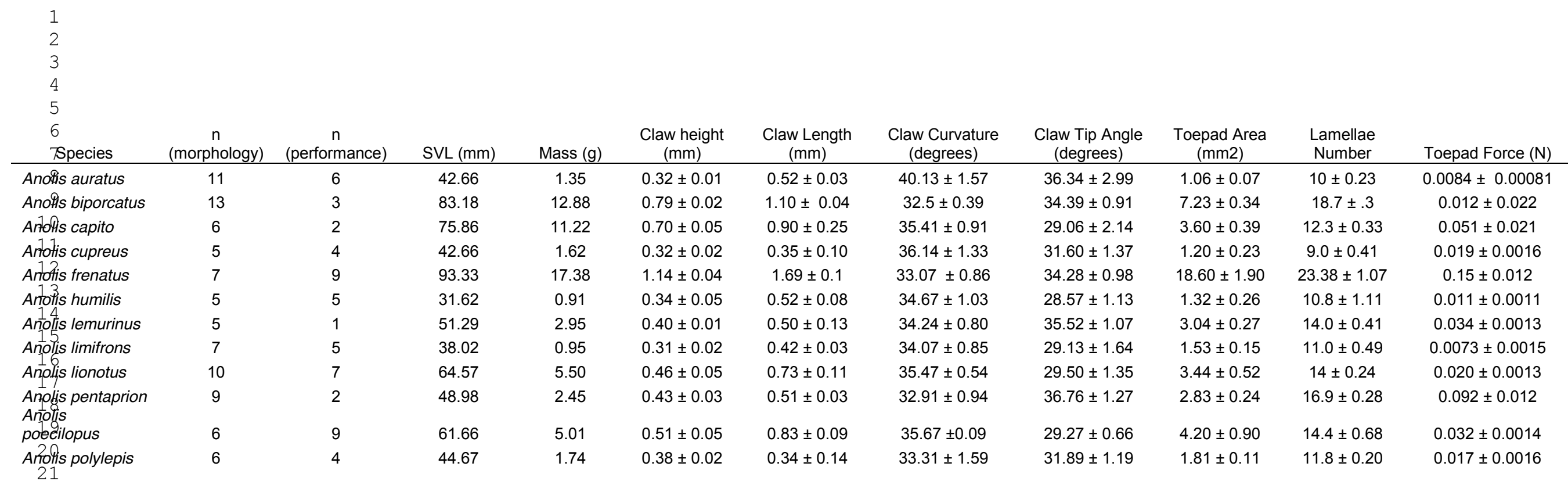




\begin{tabular}{lcccccc}
\multicolumn{1}{c}{ Species } & $\begin{array}{c}\mathrm{n} \\
\text { (morphology) }\end{array}$ & $\begin{array}{c}\mathrm{n} \\
\text { (performance) }\end{array}$ & SVL $(\mathrm{mm})$ & Mass $(\mathrm{g})$ & $\begin{array}{c}\text { Claw height } \\
(\mathrm{mm})\end{array}$ & $\begin{array}{c}\text { Claw Length } \\
(\mathrm{mm})\end{array}$ \\
\hline Anolis auratus & 11 & 6 & 42.66 & 1.35 & $0.32 \pm 0.01$ & $0.52 \pm 0.03$ \\
Anolis biporcatus & 13 & 3 & 83.18 & 12.88 & $0.79 \pm 0.02$ & $1.1 \pm 0.04$ \\
Anolis capito & 6 & 2 & 75.86 & 11.22 & $0.70 \pm 0.05$ & $0.90 \pm 0.25$ \\
Anolis cupreus & 5 & 4 & 42.66 & 1.62 & $0.32 \pm 0.02$ & $0.35 \pm 0.10$ \\
Anolis frenatus & 7 & 9 & 93.33 & 17.38 & $1.14 \pm 0.04$ & $1.69 \pm 0.1$ \\
Anolis humilis & 5 & 5 & 31.62 & 0.91 & $0.34 \pm 0.05$ & $0.52 \pm 0.08$ \\
Anolis lemurinus & 5 & 1 & 51.29 & 2.95 & $0.40 \pm 0.01$ & $0.50 \pm 0.13$ \\
Anolis limifrons & 7 & 5 & 38.02 & 0.95 & $0.31 \pm 0.02$ & $0.42 \pm 0.03$ \\
Anolis lionotus & 10 & 7 & 64.57 & 5.50 & $0.46 \pm 0.05$ & $0.73 \pm 0.11$ \\
Anolis pentaprion & 9 & 2 & 48.98 & 2.45 & $0.43 \pm 0.03$ & $0.51 \pm 0.03$ \\
Anolis poecilopus & 6 & 9 & 61.66 & 5.01 & $0.51 \pm 0.05$ & $0.83 \pm 0.09$ \\
Anolis polylepis & 6 & 4 & 44.67 & 1.74 & $0.38 \pm 0.02$ & $0.34 \pm 0.14$
\end{tabular}




\section{Figure01}

Click here to download high resolution image
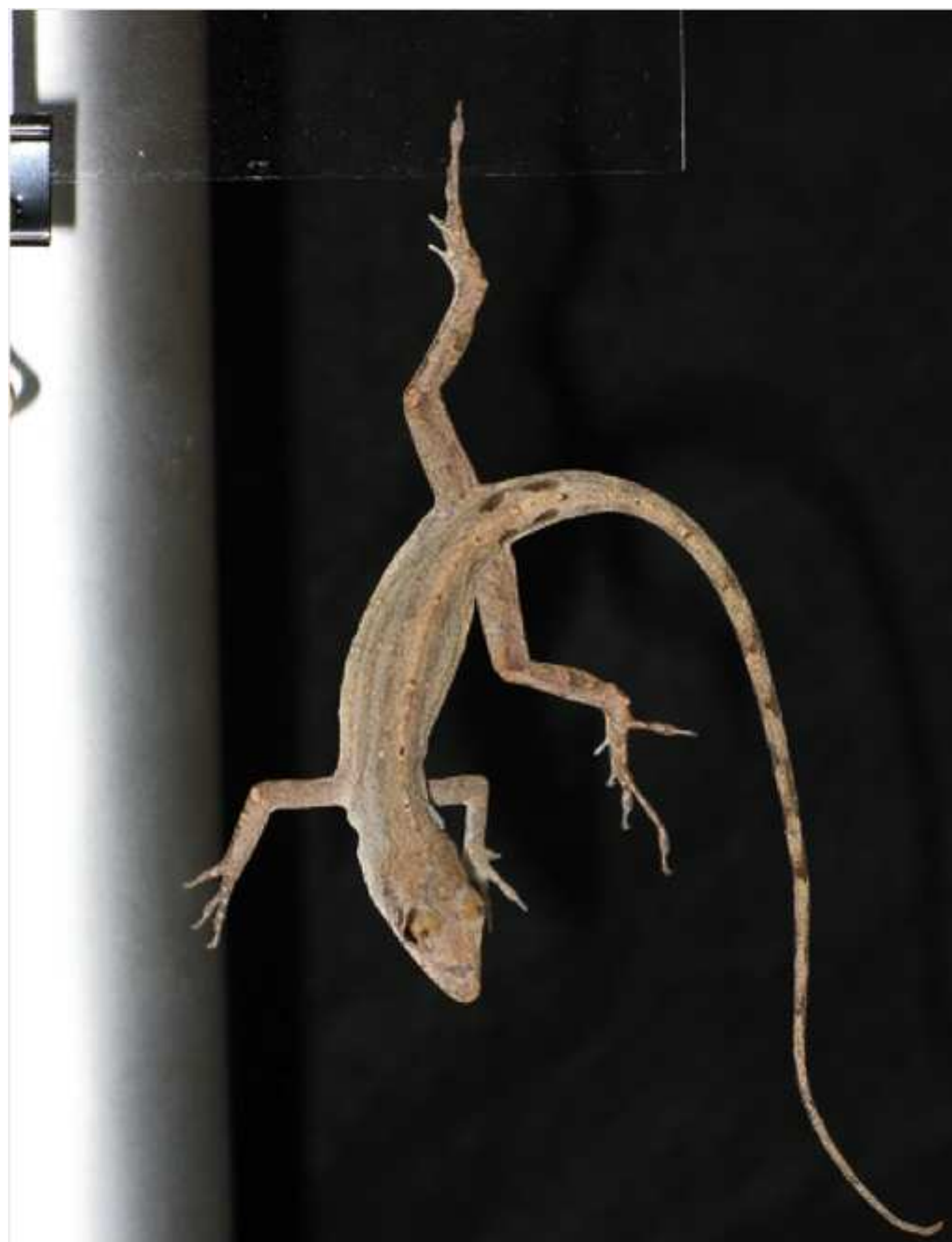
Figure02

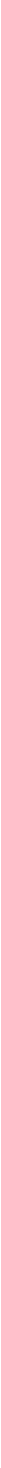

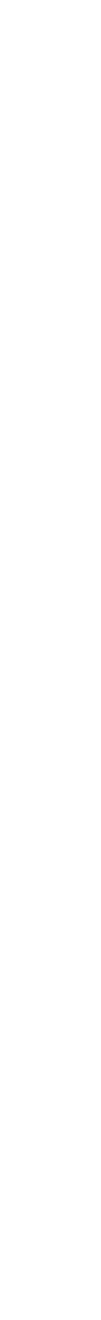
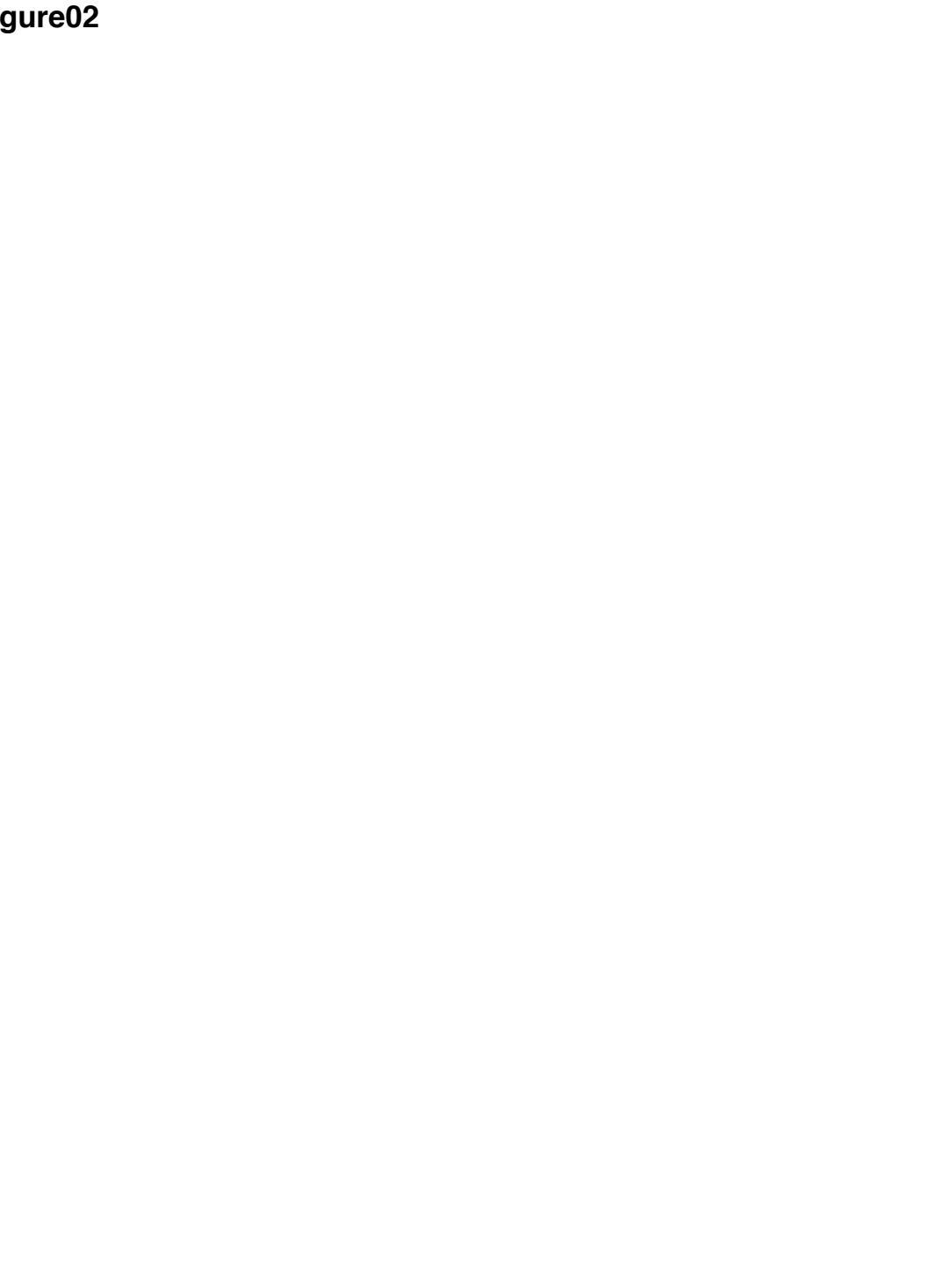
Anolis auratus

Anolis pentaprion

Anolis biporcatus

Anolis cupreus

Anolis polylepis

Anolis capito

Anolis humilis

Anolis lemurinus

Anolis limifrons

Anolis poecilopus

Anolis lionotus 
Figure05

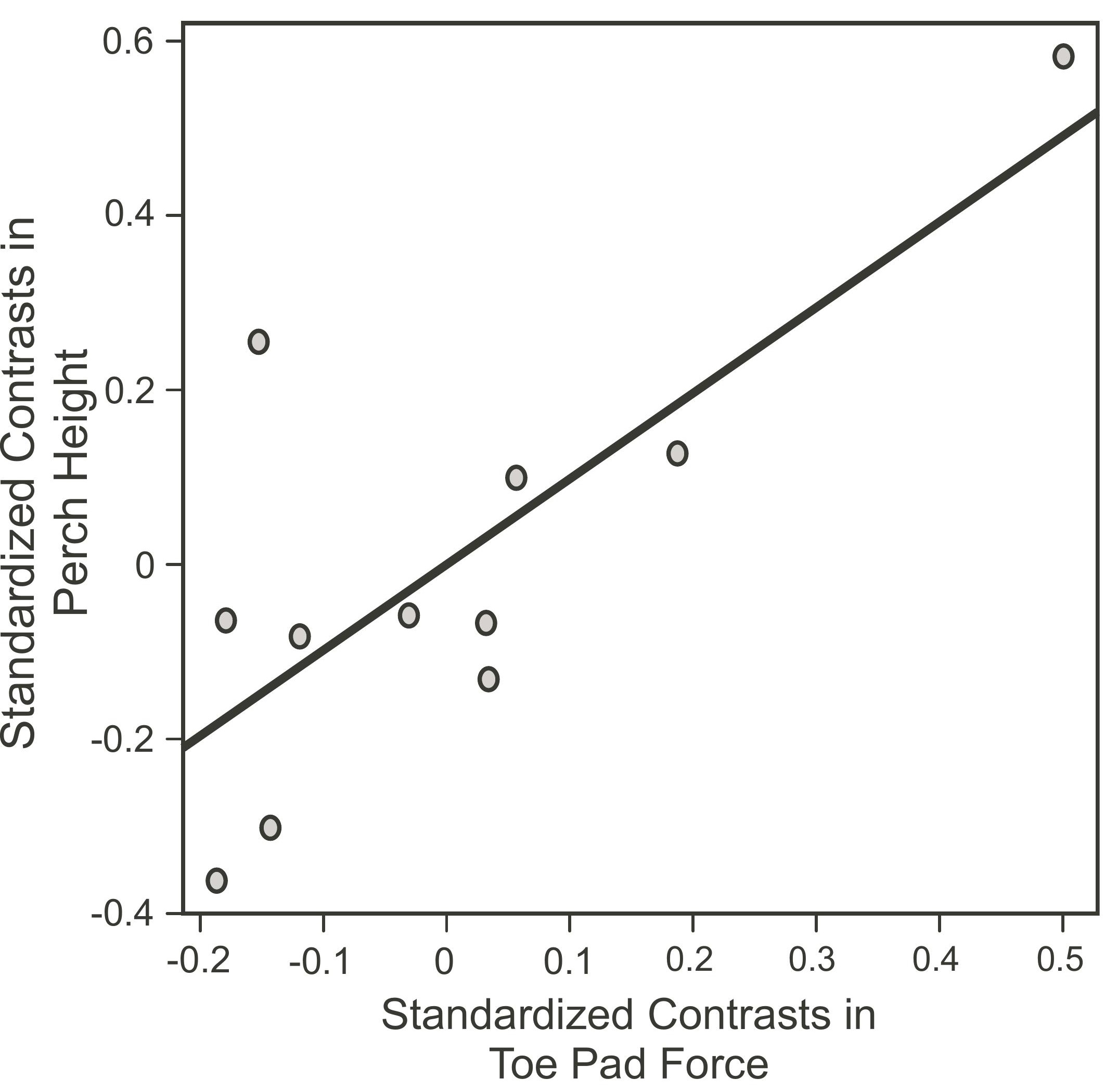

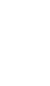

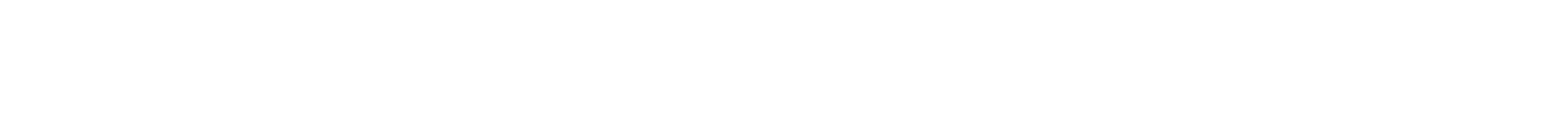

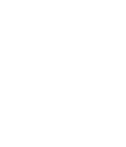
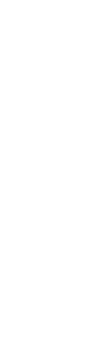

(

(6)

Figure05 


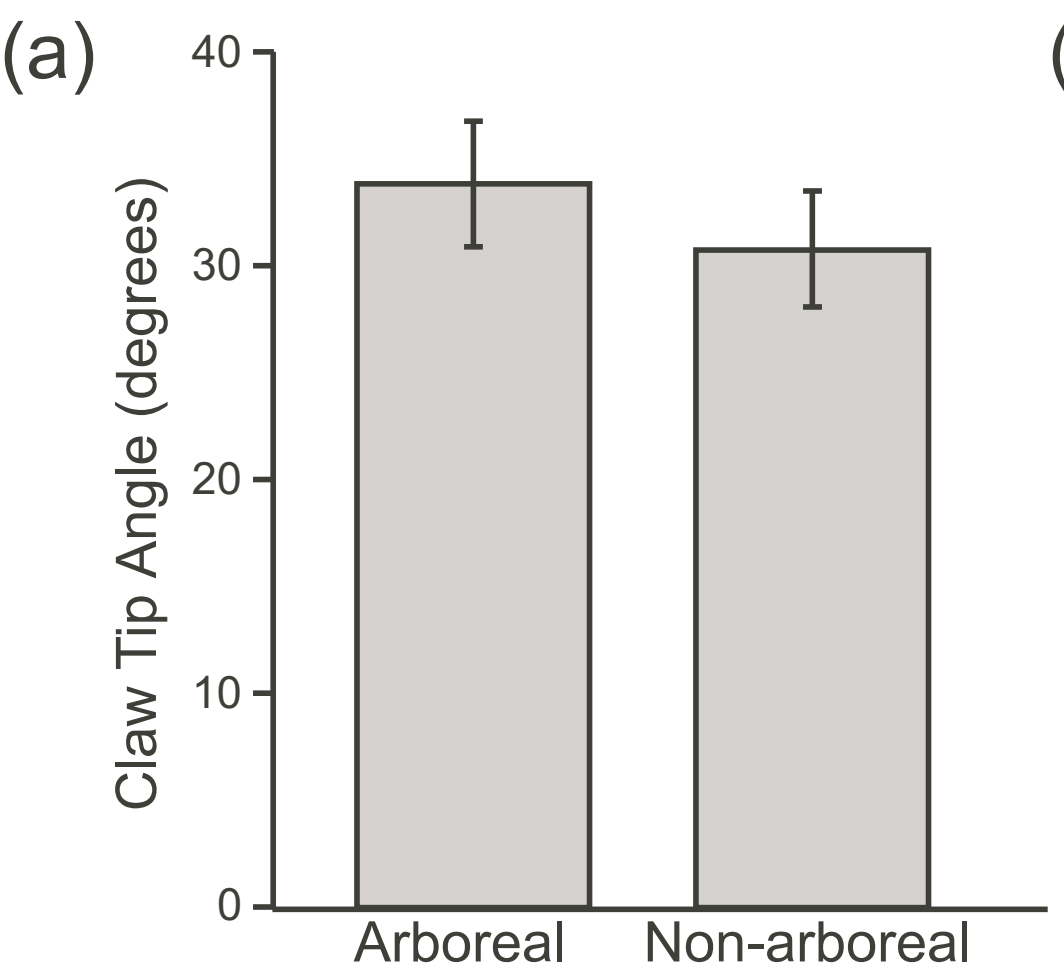

(b)

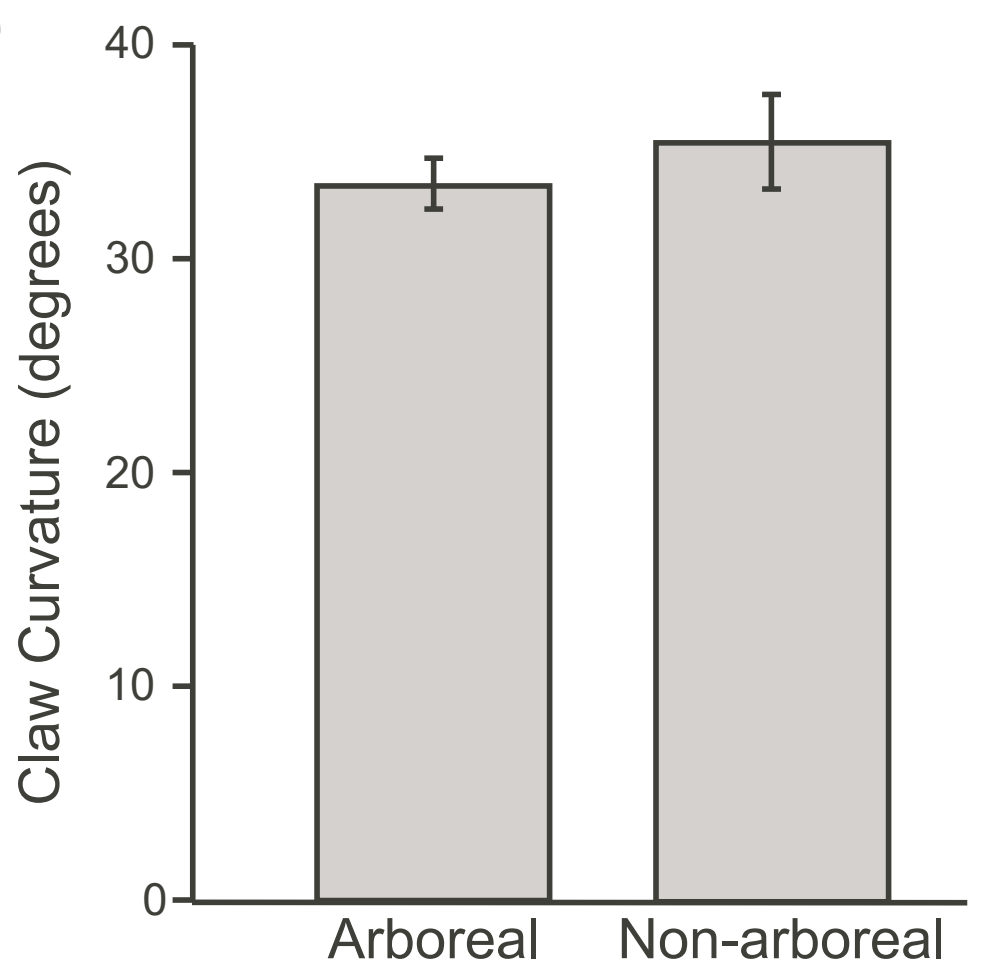

(c

(c) ${ }^{1.0} 7$

(d) $\left.{ }^{1.0}\right]$

응

0.5

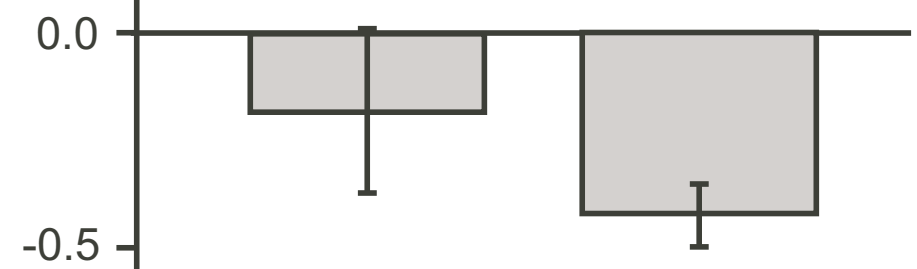

$-1.0$

Arboreal Non-arboreal 
e-component
Click here to download e-component: appendix.xIsx

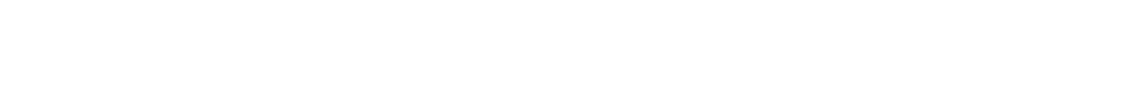
(2) 